

\title{
As Relações e os Atravessamentos das Questões de Gênero no Ensino: Uma Análise da Revista Latino-Americana de Geografia e Gênero
}

Las Relaciones y los Cruces en las Temáticas de Género en la Enseñanza: Un Análisis de la Revista Latino-Americana de Geografía y Género

\author{
Relations and Intersections of Gender Issues in Teaching: An Analysis of the \\ Latin American Journal of Geography and Gender
}

\section{Resumo}

O presente trabalho possui, como tema central, investigar a categoria de gênero e a sua abordagem na Revista Latino-americana de Geografia e Gênero, tendo como objetivo analisar as produções científicas do periódico, entre os anos de 2010 e 2019. Caracteriza-se por uma abordagem qualitativa, tendo como metodologia a pesquisa documental e bibliográfica. A seleção de trabalhos resultou num total de doze artigos, que foram divididos e apreciados nas categorias de Educação e Ensino de Geografia. A partir das análises foi concluído que é indispensável trabalhar a temática de gênero dentro da geografia. $O$ ensaio social desses estudos permite que os/as estudantes compreendam as diferentes formas de empoderamento do local por parte dos diferentes grupos sociais.

Palavras-Chave: Gênero; Educação; Ensino de Geografia; Estudos Feministas; Geografias Feministas.

El presente trabajo posee, como tema central, investigar la categoría de género y su enfoque en la Revista Latino-americana de Geografía y Género, teniendo como objetivo analizar las producciones científicas del periódico, entre los años 2010 y 2019. Se caracteriza por un enfoque cualitativo, teniendo como metodología la búsqueda documental y bibliográfica. La selección de trabajos resultó en un total de doce artículos, que fueron divididos y evaluados en las categorías de Educación y Enseñanza de Geografía. A partir de los análisis se concluyó que es indispensable trabajar la temática de género dentro de la geografía. El ensayo social de esos estudios permite que los estudiantes comprendan las diferentes formas de empoderamiento de lo local por parte de los diferentes grupos sociales.

Palabras-Clave: Género; Educación; Enseñanza de Geografía; Estudios Feministas; Geografías Feministas.

\section{Abstract}

The present work has as its central purpose to investigate the gender category and its approach in the Latin American Journal of Geography and Gender, aiming to analyze the scientific productions of this journal between 2010 and 2019. It adopts a qualitative approach, and the documentary and bibliographic research as its methodology. The selection of papers resulted in a total of twelve articles, which were evaluated and distributed in the categories of Education and Geography Teaching. From the analyses, it was concluded that it is indispensable to work with the theme of gender within geography studies. The social essay of these studies allows students to understand the different forms of local empowerment by different social groups.

Keywords: Gender; Education; Geography teaching; Feminist Studies; Feminist Geographies.

Amábili Fraga, Rosa Elisabete Militz Wypyczynski Martins 
Desde a primeira onda do movimento feminista, com as manifestações do movimento sufragista na virada do século XIX, no qual as mulheres foram às ruas para reivindicar seu direito ao voto, a questão do gênero é levantada para que possa se discutir os seus papéis na sociedade contemporânea. Mas é a partir da década de 60 que, de fato, se iniciam os estudo da mulher, a partir das discussões políticas trazidas por militantes feministas dentro das universidades e escolas (LOURO, 2004). As diferenças físicas e biológicas entre os sexos foram usadas ao longo da história para inferiorizar e invisibilizar mulheres em relação aos homens. Com o passar dos tempos e com a emergência dos estudos de gênero, estudiosas feministas passaram a rejeitar o determinismo biológico implícito nas relações sociais, laçando mão de um caráter fundamentalmente político e social das distinções baseadas unicamente no sexo. Dessa forma, as diferenças entre os sexos passam a ser vistas para além de uma questão biológica, ou seja, como um produto das culturas produzidas a partir da biologia dos corpos, e, por esse motivo fez-se necessário a discussão sobre o gênero como uma categoria de análise, possibilitando tal compreensão como uma construção social, com a finalidade de desnaturalizar a opressão feminina. (REIS, 2015).

Trilhado esse caminho, assumimos a conceituação de gênero como adotada por Scott (1995), que se refere ao modo como as diferenças sexuais entre homens e mulheres são construídas. Esta construção estaria ligada às particularidades socioculturais, que se modela de forma distinta para homens e mulheres, no qual é estabelecido o que é considerado feminino e masculino, bem como o que é destinado a cada um deles. Seria, assim, o conhecimento a respeito das diferenças sexuais e tudo o que é constituído a partir das relações sociais. É importante salientar que a questão de gênero não é negar a biologia dos corpos, pois nos constituímos sobre corpos sexuados, mas sim de que maneira nos construímos social e historicamente a partir desses corpos construídos por tais características biológicas.

No atual momento político e histórico, as discussões de gênero são cada vez mais pautadas e colocadas em voga dentro do âmbito acadêmico, escolar e na sociedade em geral. Ainda se reproduz um modelo, em que, no século XXI, mulheres e homens recebem tratamentos diferentes e as relações traçadas a partir disso refletem cotidianamente na ocupação e transformação dos espaços. A ciência geográfica tem como objeto de estudo do espaço, para tal, utilizamos as cinco categorias geográficas que auxiliam na compreensão da ação humana modelando a superfície terrestre (REIS, 2015). Essas categorias são compreendidas por: espaço, lugar, paisagem, região e território. O espaço geográfico se forma e se transforma a partir das relações sociais. Ele é gerado a partir do trabalho desempenhado por homens e mulheres. O trabalho define a natureza social do espaço e as formas como este é apropriado, devendo ser analisado como produto social, no qual a coletividade transforma o meio com base no trabalho, "esse processo determina a gênese social do espaço geográfico" (REIS, 2015, p. 21).

A sociedade contemporânea é representada pela diversidade dos sujeitos e pela maneira com que ocupam esse espaço. A apropriação desse ocorre, muitas

Amábili Fraga, Rosa Elisabete Militz Wypyczynski Martins 
As Relações e os Atravessamentos das Questões de Gênero no Ensino: Uma Análise da

Revista Latino-Americana de Geografia e Gênero

vezes, de forma distinta, excluindo e segregando. Nessa dinâmica hierárquica e generificada, as diversidades fundam desigualdades (COSTA, 2011). Para dar conta de todas essas questões, esse estudo se caracteriza como um trabalho qualitativo, utilizando como metodologia a pesquisa bibliográfica. Tendo como problemática buscar qual a potência educativa das produções científicas da Revista Latino-americana de Geografia e Gênero sobre os estudos de gênero e como possibilitam movimentar outras geografias. Apresentada a problemática, tem-se como objetivo geral analisar a produção científica da Revista Latinoamericana de Geografia e Gênero acerca dos estudos de gênero e sua relação com a educação geográfica. Identificando a trajetória dos estudos de gênero ligado a história do movimento feminista contemporâneo e sua relevância nos diferentes espaços de ensino, compreendendo qual a importância dos estudos de gênero no âmbito da geografia e, por fim, realizando um mapeamento dos artigos que abordem os estudos de gênero, tendo como indicadores de análise as categorias de educação e ensino de geografia, na Revista Latino-americana de Geografia e Gênero.

\section{Os Fios que Tecem os Caminhos Trilhados pela Pesquisa}

Esse estudo se caracteriza como um trabalho de abordagem qualitativo, utilizando como metodologia a pesquisa documental e bibliográfica. $\mathrm{Na}$ pesquisa qualitativa não existe uma preocupação com a representatividade numérica, mas, sim, com a compreensão e interpretação das questões abordadas na produção de conhecimentos acerca de fenômenos humanos e sociais. Busca-se, assim, uma justificativa para os acontecimentos, sem quantificar as trocas simbólicas, visto que os dados analisados não são métricos (SILVEIRA; CÓRDOVA, 2009). Já a escolha pelo método documental e bibliográfico se dá em razão de esse ser fundamentado em materiais obtidos a partir de documentos escritos, ou seja, fontes bibliográficas. Essa pesquisa se sustenta na análise de artigos já publicados, a fim de obter informações existentes e, baseado nisso, produzir novos dados e conhecimentos. Minha escolha de material empírico de análise foi a Revista Latino-Americana de Geografia e Gênero, por ser um periódico específico da área da geografia, que trabalha com questões de gênero e sexualidade.

A Revista Latino-americana de Geografia e Gênero tem o propósito de publicar artigos científicos que estejam ligados à área da geografia, do gênero e das sexualidades, colaborando com o desenvolvimento dos conhecimentos metodológicos e teóricos dessa área de estudo. Ademais, o periódico também busca estimular o debate acadêmico das pessoas que estão envolvidas nessas temáticas, expandindo as relações com profissionais tanto do Brasil e América Latina quanto de outras regiões do mundo a partir do uso da mídia eletrônica. A revista foi fundada no ano de 2009 , tendo seu primeiro exemplar publicado no ano de 2010, configurando-se como uma publicação semestral, sendo assim, com dois exemplares por ano, contendo em seu corpo artigos, resenhas e entrevistas. Essa é mantida pelo Grupo de Estudos Territoriais (GETE) da Universidade Estadual de Ponta Grossa (UEPG) e possibilita o livre acesso aos trabalhos. Desde que foi fundada já foram publicados 20 volumes com reflexões de pesquisadores do Brasil, Argentina, Portugal, Inglaterra, Espanha,

Amábili Fraga, Rosa Elisabete Militz Wypyczynski Martins 
Eleito o instrumento e aliado à ânsia de pesquisar sobre as questões de gênero dentro da educação geográfica, entramos na etapa de seleção das categorias a serem examinadas. Sendo assim, no campo de pesquisa disponível no site do periódico elegemos como indicadores de busca as seguintes palavras: educação, ensino, educação geográfica, ensino de geografia e escola. A pré-seleção de trabalhos resultou num total de 247 artigos, entre os anos de 2010 e 2019, que tiveram seus títulos e resumos previamente lidos, e a partir dessa primeira análise, alicerçada aos objetivos dessa pesquisa, foram selecionados doze artigos.

Os artigos foram previamente investigados e, a partir da leitura introdutória dos títulos, resumos e palavras-chave, foi possível a indicação de duas grandes categorias que englobassem todos esses trabalhos para a realização das análises. As categorias de análise elencadas para realizar essa pesquisa e, posteriormente, alcançar meu objetivo geral foram: Educação e Ensino de geografia.

\section{O Movimento Feminista e as Questões de Gênero}

Quando falamos de gênero, falamos também da história do movimento feminista. No Brasil, as lutas feministas tiveram início no século XIX, reconhecida como a primeira onda, surgindo a Federação Brasileira pelo Progresso Feminino. Buscava-se, assim, lutar pelo direito ao trabalho e pelo sufrágio feminino, sendo esse um amplo movimento ocorrido em vários países democráticos do mundo, entre o fím do século XIX e o início do século XX, para organizar a luta das mulheres pelo direito ao voto.

Tal movimento teve grande repercussão em inúmeros países ocidentais. Nessa fase as lutas eram, em geral, capitaneadas por mulheres brancas e de classe média. Em 1970 tem início a segunda fase de disputas, no qual, além do direito ao trabalho, as mulheres lutaram contra a violência sexual e contra a ditadura militar. Nesse período, no Brasil, no ano de 1975 nasce o Movimento Feminino pela Anistia e também o jornal Brasil Mulher, que ficou em circulação por cinco anos (RIBEIRO, 2018). A militância feminina se fez presente também dentro das universidades e é nesse contexto de lutas políticas, na segunda onda do movimento feminista, que surgem então os primeiros estudos da mulher (LOURO, 1997).

O feminismo possibilitou a crítica aos modelos de dominação e subordinação da mulher, demonstrou as desigualdades sociais entre homens e mulheres no acesso ao direito à educação, ao voto, ao patrimônio familiar, à justiça, ao trabalho, a bens materiais etc.; questionou as representações acerca do "ser mulher" e do "ser feminino" (FURLANI, 2016, p. 58).

No início do movimento era imprescindível para as feministas que estavam na luta, que as mulheres deixassem de ser ocultadas e passassem a se tornar seres visíveis, inclusive dentro das universidades. Essa invisibilidade era determinada a partir dos discursos que sentenciavam mulheres e homens, tendo o espaço da mulher limitado ao doméstico. De fato, muitas mulheres já haviam

Amábili Fraga, Rosa Elisabete Militz Wypyczynski Martins 
As Relações e os Atravessamentos das Questões de Gênero no Ensino: Uma Análise da

Revista Latino-Americana de Geografia e Gênero

lutado para superar e derrubar essa barreira, e, com a força do movimento mais e mais mulheres começaram a ocupar diferentes espaços, como lojas e hospitais. Porém, tais atividades, em grande parte, eram comandadas e dirigidas por homens (LOURO, 1997).

Para perceber e compreender as relações de homens e mulheres em determinado espaço, é preciso atentar ao que é socialmente construído sobre os sexos, assim, gênero se torna uma categoria necessária para análise dessas relações (LOURO, 1997). A partir de Scott (1995) percebemos que a categoria gênero ultrapassa as diferenças sexuais entre os corpos. Para a autora o que toca no real sentido da palavra é a construção das significações culturais para tais diferenças, se formando as relações hierárquicas. Gênero, para Scott, foi teorizado como uma categoria, tal como raça e classe social, utilizada para a análise das relações de poder (REIS, 2015). Ao refletir sobre o conceito e transcendê-lo para a escola, identificamos as relações hierárquicas que se formam dentro de tal espaço.

Desde a conquista do voto, as mulheres vêm ganhando espaço em todas as esferas da sociedade, e por mais que esses avanços ocorram de forma lenta, muitos passos já foram avançados e muitos espaços conquistados por elas. Assim como os estudos referente as mulheres, os estudos de gênero também estão cada vez mais presentes, tanto na sociedade, quanto nos espaços educativos, porém, ainda vemos grande resistência quando falamos em levar gênero para as salas de aula. Dessa forma, destacamos a importância das pesquisas referentes a esses temas e a necessidade de levar esses estudos para as mais diferentes áreas do ensino. É importante que a história do movimento feminista seja difundida, assim como as diferenças de gênero passam a ser reconhecidas e as desigualdades diminuídas.

\section{As Relações de Gênero no Espaço Escolar}

A escola que temos hoje tem sua historicidade ligada ao final da idade média e à organização da sociedade moderna (PETITAT, 1994). Desde o seu início, está ancorada em mecanismos de disciplina e controle que, por muito tempo, se transformou em um espaço de produção de segregação, exclusivo para uma determinada classe social, no qual uma imensa maioria da população não tinha acesso à escola e era analfabeta. Com um sistema extremamente autoritário e conservador, a escola separava, inicialmente, adultos de crianças, católicos de protestantes, ricos de pobres, e até meninas de meninos. Foi um período marcado por desigualdades com uma rígida organização espacial da sala de aula, com rotinização das atividades e padronização de normas disciplinares, que contribuía para reforçar as diferenças.

A escola contribui na formação da identidade e na construção dos valores dos/das estudantes, onde, muitas vezes, o papel de meninas e meninos são estabelecidos. "Ali se aprende a olhar e a se olhar, se aprende a ouvir, a falar e a calar; se aprende a preferir" (LOURO, 1997, p. 61). Essa dinâmica, que por muito tempo foi naturalizada, passa a ser questionada e surgem movimentos que buscam mudanças de paradigmas e uma escola voltada para a diversidade dos/das estudantes oriundos(as) de contextos diferentes e realidades distintas. Com isso, o que é tomado como natural passa a ser questionado.

Amábili Fraga, Rosa Elisabete Militz Wypyczynski Martins 
As Relações e os Atravessamentos das Questões de Gênero no Ensino: Uma Análise da

Revista Latino-Americana de Geografia e Gênero

A escola tem um papel central na produção e difusão do conhecimento e contribui na formação dos(as) estudantes. Mas é preciso reconhecer que essa formação, ao longo da história, se efetivou a partir de relações desiguais e hierárquicas, por meio de diferentes dispositivos que contribuíram para reforçar os estereótipos sociais. Mais importante do que reconhecer essas práticas é questioná-las e discuti-las, é dar suporte para que os(as) estudantes compreendam a importância de estudar as temáticas que tratam sobre gênero e saibam que homens e mulheres têm os mesmos direitos e têm que ser reconhecidos(as) na sociedade num patamar de igualdade. Ao trabalhar com essas discussões na escola e problematizar as relações de poder empregadas nesse lugar, dá-se espaço e visibilidade para as diferentes identidades, para que todos e todas possam se conhecer e se reconhecer.

\section{Geografias Feministas: O Lugar de Encontro entre o Gênero e a Ciência Geográfica}

A ciência geográfica é marcada por privilégios, no qual quem não se encaixa no padrão masculino, branco e heterossexual acaba por ter suas espacialidades menos expressas, como acontece com as mulheres. Para compreender essa invisibilidade, é necessário perceber que o discurso geográfico hegemônico e naturalizado cria barreiras para as indagações produzidas pelas diversidades em suas mais diversas espacialidades. Porém, essas minorias vêm ganhando força e espaço ao buscar um contrapoder a essa normatização (SILVA, 2009). Nessa lógica, surgem as geografias feministas, que buscam "desafiar a crença fundamentalista da universalidade do saber geográfico estabelecido, por meio da reivindicação de novas versões científicas" (SILVA, 2009, p. 26). Nessa geografia, o gênero e suas espacializações podem se justapor. Esse movimento se manifesta com muito mais força nas universidades europeias, enquanto no Brasil, essa mobilização ainda é pouco expressiva e possui pequena influência no discurso geográfico (SILVA, 2009).

A intenção dos estudos feministas é pesquisar e estudar o que é ser mulher desde a antiguidade até o contemporâneo, como essa categoria se diversifica nos diferentes espaços e tempos e a maneira como é regulada pela cultura dentro da sociedade. Nas palavras de Bell Hooks (2019), o feminismo é um movimento para acabar com o sexismo, exploração sexista e opressão, e é a isto que nossas pesquisas servem. Desnaturalizamos o que é ser mulher por meio da categoria de gênero, pois buscamos popularizar cientificamente que esta é uma construção social e cultural, e não designada naturalmente porque somos fêmeas. Espacialmente isso implica dizer que mulheres não devem ocupar somente espaços privados, mas também públicos, etc.

É necessário reconhecer que, mesmo com a intenção de abarcar todas as mulheres, dentro dos estudos feministas cada uma assume seu lugar de fala, a partir de suas experiências e vivências quanto as suas questões de identidade, raça, etnia, sexualidade e classe social. A luta de mulheres brancas, de classe média em países considerados 'desenvolvidos', é diferente da luta que as mulheres negras, de classe baixa, em países subdesenvolvidos enfrentam. Uma não desmerece nem diminui a importância das outras, mas essa união e o

Amábili Fraga, Rosa Elisabete Militz Wypyczynski Martins 
reconhecimento dessas diferenças fortalecem a luta pela igualdade perante a supremacia masculina. O foco desses estudos são as desigualdades entre homens e mulheres para a busca de novos pontos de encontro de interesses, significados, linguagens e a representação da definição de gênero (REIS, 2015).

A concepção de gênero a partir da perspectiva pós-estruturalista trouxe para os estudos de gênero novas possibilidades a partir das análises do espaço como uma unidade importante nas concepções feministas. Esse espaço, concebido como social, material e dinâmico, necessita de uma investigação da sociedade e da natureza, assim como o resultado da correlação de ambas. "A análise do espaço requer as noções conceituais construídas acerca da espacialidade, valorizando a formação da consciência territorial, interpretando as territorialidades" (REIS, 2017, p.31). São nas territorialidades que as localidades se estruturam a partir das ações vivenciadas, permitindo estabelecer os agentes sociais, buscando não somente identificar elementos que a compõem, mas ressaltar as subjetividades, considerando que a compreensão do espaço também leva em consideração as relações dos sujeitos.

\section{Os Estudos de Gênero no Ensino de Geografia}

Por ser uma ciência que busca desenvolver nos cidadãos a consciência dos seus direitos e deveres, é importante que a geografia promova discussão e estudos com temas relacionados à produção do espaço e às reações que são produzidas neste espaço.

A geografia escolar se constitui como um componente do currículo, e, seu ensino, se caracteriza pela possibilidade de que os estudantes percebam a singularidade de suas vidas e, reconheçam a sua identidade e o seu pertencimento em um mundo que a homogeneidade apresentada pelos processos de globalização trata de tornar tudo igual. $\mathrm{E}$, portanto uma matéria curricular que encaminha a compreender o mundo e, às pessoas a se entenderem como sujeitos neste mundo, reconhecendo a espacialidade dos fenômenos sociais (CALLAI, 2011, p. 129).

A geografia pode possibilitar a compreensão das relações humanas utilizando de temas considerados transversais, como é o caso dos estudos de gênero para forjar outras formas de trabalhar este campo do conhecimento, no sentido de ampliar as experiências dos/das estudantes para além dos limites estreitos do saber disciplinar e conteudista.

Por serem questões sociais, os Temas Transversais têm natureza diferente das áreas convencionais. Tratam de processos que estão sendo intensamente vividos pela sociedade, pelas comunidades, pelas famílias, pelos alunos e educadores em seu cotidiano. São debatidos em diferentes espaços sociais, em busca de soluções e de alternativas, confrontando posicionamentos diversos tanto em relação à intervenção no âmbito social mais amplo quanto à atuação pessoal. São questões urgentes que interrogam sobre a vida humana, sobre a realidade que está sendo construída e que demandam transformações macrossociais e também de atitudes pessoais, exigindo, portanto, 
As Relações e os Atravessamentos das Questões de Gênero no Ensino: Uma Análise da

Revista Latino-Americana de Geografia e Gênero

ensino e aprendizagem de conteúdos relativos a essas duas dimensões (MEC/SEF, 1998, p. 26)

Quando se trabalha gênero na geografia, é necessário um olhar atento para a desconstrução de estereótipos que reforcem as desigualdades entre os gêneros, auxiliando na formação de estudantes conscientes de uma sociedade plural. Ao tratar da produção espacial, a geografia busca atingir uma neutralidade em suas abordagens, porém, essa neutralidade acaba assumindo a óptica de uma sociedade patriarcal de dominação masculina, dando invisibilidade à mulher (SILVA, 2003). Para reconhecer a mulher como detentora do espaço, assim como os homens, é necessário prestar atenção nos grupos que foram marginalizados. Quando trazemos as discussões de gênero para a geografia, podemos fazer uma relação entre as relações de poder advindas dessa categoria e problematizar como essas se dão na ocupação do espaço.

Tanto na educação básica quanto no ensino superior, a geografia possui margem para trabalhar as questões de gênero. Os movimentos sociais que vêm ganhando força, lutando pelos direitos de mulheres, gays, travestis e outros, dão amparo para as discussões de gênero dentro da geografia, a partir do reconhecimento das diversidades e de que maneira essas ações modelam o espaço, assumindo-a como uma ciência que estuda as relações que ocorrem no mesmo. A geografia escolar pode oferecer aos estudantes possibilidades para compreender e intervir na realidade social, ou seja, reconhecer como a sociedade se relaciona com a natureza na construção de determinado local. Neste sentido, é fundamental que seja abordado nas aulas de geografia, temáticas sobre as questões de gênero e as diversidades, pois a escola precisa estar aberta aos fenômenos que são resultados da vida em sociedade.

\section{Educação e Ensino de Geografia: Uma Análise}

O cenário da Educação perpassa por inquietações e indagações que nos levam a refletir sobre as práticas pedagógicas instauradas no cotidiano escolar. Esses anseios estão relacionados à busca por uma educação que possa contribuir na formação dos(as) estudantes, frente a uma sociedade que vive em constante mudança. Considerando que a escola forma seus sujeitos, é necessário reconhecer que esse processo é vivenciado a partir de relações desiguais que precisam ser discutidas e questionadas.

Com isso, trabalhar com as questões de gênero na educação dá suporte para ultrapassar os estereótipos culturalmente construídos, formando sujeitos aptos a reconhecer e a respeitar as diversidades. A geografia enquanto disciplina, aliada a escola, possibilita que os(as) estudantes construam um conhecimento quanto às diversidades. Logo, podemos destacar que o ensino de geografia no âmbito escolar, deve abordar as questões espaciais através das relações humanas, levando em consideração a categoria de gênero, tornando o espaço escolar plural.

Para compor o corpus da pesquisa, foram selecionados doze artigos que serão expostos separadamente de acordo com os indicadores de análise de Educação e Ensino de Geografia da referida revista. A tabela a seguir traz a relação de artigos que serão apreciados nessa pesquisa, dentro da categoria Educação. Os artigos estão caracterizados a modo de identificar: o título do

Amábili Fraga, Rosa Elisabete Militz Wypyczynski Martins 
As Relações e os Atravessamentos das Questões de Gênero no Ensino: Uma Análise da

\section{Revista Latino-Americana de Geografia e Gênero}

trabalho, os/as autores(as), ano de publicação e o volume e número da edição. Neste ponto, todos os trabalhos indicados foram apreciados de maneira precisa e individual, para que fosse possível realizar uma análise geral dos trabalhos a fim de concluir como esses se correlacionam com as temáticas elencadas.

Tabela 1: Artigos da Revista Latino-Americana de Geografia e Gênero selecionados para análise na categoria Educação

\begin{tabular}{|c|c|c|c|c|}
\hline Título & $\begin{array}{l}\text { Categoria } \\
\text { de Análise }\end{array}$ & Autor (a/es) & Ano & $\begin{array}{l}\text { Volume/ } \\
\text { Número }\end{array}$ \\
\hline A Escola em Diáspora & Educação & $\begin{array}{lr}\text { CORREA, } & \text { Anderson } \\
\text { Rodrigues; } & \text { FREITAS, } \\
\text { Letícia Fonseca Richthofen }\end{array}$ & 2011 & v. 2, n. 2 \\
\hline $\begin{array}{l}\text { As Educadoras e o } \\
\text { Sistema de Ensino do } \\
\text { Município de Porto } \\
\text { Velho: Uma História } \\
\text { de ausências }\end{array}$ & Educação & $\overline{\text { BASILIO; Luciana }}$ & 2014 & v. 5, n. 2 \\
\hline $\begin{array}{lr}\text { "Não, Isso não é Coisa } \\
\text { pra Homem" } \\
\text { Masculinidades e } \\
\text { Processos } \\
\text { Inclusão/Exclusão em } \\
\text { uma Escola da Baixada } \\
\text { Fluminense - RJ }\end{array}$ & Educação & $\begin{array}{l}\text { BRITO, Leandro } \\
\text { de; Teofilo } \\
\text { Guilherme de Oliveira; } \\
\text { SANTOS, Mônica Pereira } \\
\text { dos }\end{array}$ & 2014 & v. 5, n. 2 \\
\hline $\begin{array}{lr}\text { Significações de um } \\
\text { personagem } & \text { de } \\
\text { desenho animado no } \\
\text { espaço escolar: um } \\
\text { estudo sobre gênero na } \\
\text { Educação Infantil }\end{array}$ & Educação & $\begin{array}{l}\text { CORREIO, Juliana Lopes } \\
\text { Garcia; TOSCANO, Carlos }\end{array}$ & 2016 & v. 7, n. 1 \\
\hline $\begin{array}{lr}\text { Estudo } & \text { das } \\
\text { Representações } & \text { Sociais } \\
\text { de Professores Homens } \\
\text { de Mato Grosso do Sul } \\
\text { Sobre o } & \text { Trabalho } \\
\text { Realizado } & \text { com } \\
\text { Crianças } & \end{array}$ & Educação & $\begin{array}{l}\text { GONÇALVES, Josiane } \\
\text { Peres; } \quad \text { CARVALHO, } \\
\text { Viviane de Souza Correia }\end{array}$ & 2016 & v. 7, n. 2 \\
\hline $\begin{array}{l}\text { Alienígenas na Escola: } \\
\text { Corpos que Escapam } \\
\text { ao Processo ro de } \\
\text { Re/Produção } \\
\text { Gêneros Imutáveis }\end{array}$ & Educação & $\begin{array}{l}\text { JUNIOR, Isaias Batista de } \\
\text { Oliveira; OLIVEIRA, } \\
\text { Marta Regina Furlan de; } \\
\text { MAIO, Eliane Rose }\end{array}$ & 2017 & v. 8, n. 1 \\
\hline 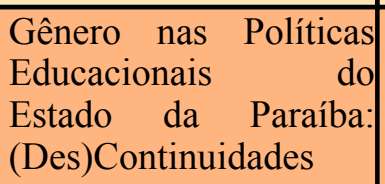 & Educação & 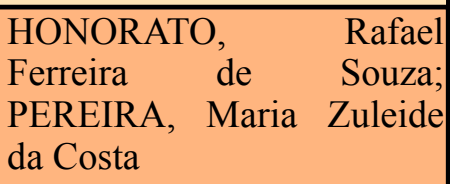 & 2017 & v. 8, n. 2 \\
\hline $\begin{array}{l}\text { Políticas públicas de } \\
\text { gênero no contexto } \\
\text { escolar: percepções de } \\
\text { orientadoras } \\
\text { educacionais }\end{array}$ & Educação & $\begin{array}{l}\text { SOUSA, Lúcia Aulete } \\
\text { Búrigo de; GRAUPE, } \\
\text { Mareli Eliane; LOCKS, } \\
\text { Geraldo Augusto }\end{array}$ & 2019 & v. 10, n. 1 \\
\hline
\end{tabular}

Fonte: Elaborada pela autora, 2019.

Amábili Fraga, Rosa Elisabete Militz Wypyczynski Martins 
As Relações e os Atravessamentos das Questões de Gênero no Ensino: Uma Análise da

Revista Latino-Americana de Geografia e Gênero

O primeiro artigo, intitulado 'A Escola em Diáspora', faz a análise do filme 'Entre os Muros da Escola'; o trabalho, embasado nos Estudos Culturais, toma os filmes como artefatos culturais. O filme traz a história de um professor que relata sua trajetória profissional em uma escola de ensino médio, na periferia de Paris. O local em questão possui grande diversidade étnica e social e o ambiente escolar que é retratado no filme apresenta-se imerso em conflitos relacionados à complexidade da sociedade contemporânea, principalmente em ambientes de periferia e vulnerabilidade social.

Os ensaios feitos se debruçam nas identidades dos sujeitos ali presentes, muitos desses, imigrantes, o que acarreta discussões acerca das identidades culturais. As questões de gênero são trabalhadas, de acordo com os autores(as), a partir de discussões entre professor(a) e estudantes sobre homossexualidade, com destaque para o preconceito por parte dos discentes. São mencionadas as questões linguísticas e o poder simbólico dessas. De acordo com Louro (2004), as identidades não são fixas, sendo a identidade heterossexual por vezes concebida como a norma, ignorando que todas as outras identidades sejam construídas socialmente. Sendo assim, as investigações feitas nesse trabalho situam os sujeitos histórico e culturalmente, problematizando as questões identitárias presentes na sociedade, focando nas identidades de gênero.

No trabalho 'As Educadoras e o Sistema de Ensino do Município de Porto Velho: Uma História de ausências' nos deparamos, primeiramente, com um panorama acerca do processo de exclusão das mulheres e a importância do papel social da escola sobre essa prática, assim como um histórico da inserção das mulheres na educação. A pesquisa realizada nesse artigo tem o objetivo de apurar o porquê da sub-representação das professoras, frisando a necessidade de políticas públicas que deem mais espaço para as mulheres nas gestões educacionais.

Além da questão de representatividade das mulheres nos sistemas de ensino, as relações de gênero são levantadas no que toca os Projetos políticos pedagógicos das escolas. Embora gênero seja um dos eixos temáticos de inclusão a ser proposto, segundo a autora, esse documento usa apenas pronomes masculinos se referindo sempre 'aos professores', supondo que as educadoras se sintam inclusas, incorporando uma noção de predomínio masculino sobre o feminino, averiguando que as questões de gênero ainda não se fazem valer na prática educativa.

Em "Não, Isso não é Coisa pra Homem" - Masculinidades e os Processos de Inclusão/Exclusão em uma Escola da Baixada Fluminense - RJ, o trabalho realiza uma pesquisa etnográfica pautada numa perspectiva de inclusão em educação referente às questões de gênero, considerando esse um processo que reconhece as diferenças no espaço escolar. É destacado a importância da inclusão neste espaço, que é formado por uma diversidade de pessoas e deve pautar suas ações num processo inclusivo. A pesquisa é fundamentada na visão de gênero a partir das relações sociais que ocorrem entre os sexos. Dessa forma, a investigação foi realizada em uma escola pública do Rio de Janeiro, com estudantes do quinto ano, tendo como objetivo observar como os processos de exclusão e inclusão influenciam nas construções das masculinidades dos/das estudantes.

De acordo com os autores(as), nos espaços escolares existe uma grande

Amábili Fraga, Rosa Elisabete Militz Wypyczynski Martins 
As Relações e os Atravessamentos das Questões de Gênero no Ensino: Uma Análise da

Revista Latino-Americana de Geografia e Gênero

pressão social e cultural sobre os meninos, baseada num comportamento masculino a partir de um modelo hegemônico de masculinidade de matriz heterossexual. Percebeu-se também a generificação das disciplinas escolares, bem como nas práticas esportivas, consequentemente, excludentes, que reforçam a oposição meninos/meninas. O trabalho concluiu que as masculinidades da turma analisada estavam influenciadas pelo sistema de inclusão e exclusão, em que a escola representa uma formadora de identidades generificadas, afirmando a regulação de um modelo de masculinidade hegemônica a ser seguido pelos meninos, afirmando-se assim, como homens na sociedade.

No trabalho 'Significações de um personagem de desenho animado no espaço escolar: um estudo sobre gênero na Educação Infantil', o objetivo foi verificar como surgem às questões de gênero com crianças de uma turma da Educação Infantil numa perspectiva histórico-cultural, através da observação. Foi possível analisar que as relações de gênero estão presentes na educação infantil tanto quanto na educação de crianças maiores e adolescentes. Os episódios que envolveram gênero surgiram no decorrer das atividades descritas pelos(as) autores(as), ou seja, essa não era uma pauta de discussão a ser. Essas questões emergiram no decorrer de brincadeiras e trocas entre as crianças. A forma como essas expressaram questões referentes ao gênero ocorreram a partir de expressões verbais, gestos e atitudes acompanhadas das escolhas de objetos e formas de brincar.

Segundo os(as) autores(as), a pesquisa foi realizada com crianças de quatro anos por ser uma idade onde é possível apreender o contexto social e cultural, expressando as questões de gênero por meio de brincadeiras. Com as observações, os(as) autores(as) concluíram que o processo de significação do que é masculino ou feminino se constrói socialmente, e, consequentemente, está relacionado ao contexto social e cultural do espaço. Assim, de acordo com a pesquisa, a consciência da criança do que é mulher ou homem e o que cabe a cada um é uma prática construída através do que é visto, assim como por meio das falas e das vivências que acontecem no âmbito familiar e são trazidos para o espaço escolar.

O quinto artigo, intitulado 'Estudo das Representações Sociais de Professores Homens de Mato Grosso do Sul Sobre o Trabalho Realizado com Crianças', traz um histórico do magistério no Brasil. Tem o objetivo de identificar as representações sociais a respeito da atividade docente de homens nos anos iniciais do ensino fundamental. O magistério, inicialmente uma profissão masculina, em que apenas homens estudavam e ensinavam, e, com o acesso das mulheres à profisssão docente, ocorreu uma feminização da profissão. A influência das escolhas a partir das relações de gênero no que diz respeito às profissões e representações sociais, é estudado e é debatido nesse trabalho.

Foram realizadas entrevistas semiestruturadas para coleta de dados com professores homens. As perguntas feitas pelas autoras abordaram os aspectos da atuação de professores homens no ensino fundamental, a impressão das crianças para com esses professores, relação com a comunidade escolar, o que os levou escolher esta profissão e acerca da pequena quantidade de homens atuando no ensino fundamental. Com base nas entrevistas as autoras puderam

Amábili Fraga, Rosa Elisabete Militz Wypyczynski Martins 
As Relações e os Atravessamentos das Questões de Gênero no Ensino: Uma Análise da

Revista Latino-Americana de Geografia e Gênero

verificar, relacionado às questões de gênero na educação, que as tarefas atribuídas a mulheres e homens na atuação profissional continuam gerando representações sociais acerca disso. As representações sobre professores homens, que continua instaurada, diz respeito a esses imporem maior autoridade e que um dos maiores obstáculos a ser enfrentado é o "cuidar das crianças", aliado as características femininas. Concluiu-se que as representações de gênero são atribuídas tanto aos professores homens quanto as mulheres e isso tem grande influência sobre a dinâmica da história da educação.

'Alienígenas na Escola: Corpos que Escapam ao Processo de Re/Produção dos Gêneros Imutáveis' é um trabalho que tem como objetivo demonstrar o encadeamento das (re)produções das identidades de pessoas Trans - travestis, transexuais e transgênero. Evidenciando as barreiras a serem enfrentadas para terem acesso aos direitos básicos no dia a dia escolar. A justificativa que permeia a escolha do tema por parte dos(as) autores(as) se dá pela percepção desses sujeitos serem rotulados no contexto escolar pela comunidade em geral, frente a um ambiente de hostilidade, resultando na evasão escolar por parte desses(as) estudantes. Definir a constituição das identidades e diferenças dos(as) estudantes Trans, reconhecer as dificuldades de permanência na escola por conta da transfobia pedagógica e exprimir os efeitos dessa pedagogia na exclusão são os objetivos específicos elencados para a pesquisa.

A maneira como se percebe a identidade de gênero, engloba o senso pessoal corporal, podendo ou não sofrer alterações de acordo com suas escolhas. Esse processo está ligado à identidade de gênero, visto que essa é a maneira como o sujeito se reconhece e como quer ser reconhecido e respeitado. Dessa forma, quando os sujeitos desviam do processo de generificação e chegam ao espaço escolar, são alvos da pedagogia do insulto. No que tange as relações de gênero, os(as) autores(as) versam que esse processo contribui para o crescimento de um sentimento de não pertencimento a este espaço, o que leva a evasão.

Sendo assim, para reverter esse cenário, os(as) autores(as) defendem a realização de programas sobre temas como sexualidades, discriminação, Transfobia, identidade de gênero e violência, não apenas na perspectiva de inclusão de professores(as), mas de toda a comunidade escolar, para que esses(as) estudantes não sofram com a expulsão imposta pelo processo de escolarização.

A pesquisa intitulada 'Gênero nas Políticas Educacionais do Estado da Paraíba: (Des)Continuidades', foi realizada no momento conjuntural em que o Brasil sofria com uma ruptura democrática com o impeachment da Presidenta Dilma e o avanço do conservadorismo na política nacional. Ao contrário de um governo que buscava avanços, o governo do presidente Michel Temer, que assumiu o poder, mostrou em suas medidas o desígnio de desestruturar esse processo, assumindo uma posição neoliberal e conservadora que afetaria a educação no país. Em meio a esse cenário, esse trabalho analisou as questões de gênero das políticas educacionais e curriculares focado na Educação de Jovens e Adultos (EJA), na rede estadual de ensino da Paraíba.

As análises feitas pelos(as) autores(as) mostraram uma grande complexidade no desenvolvimento das políticas educacionais, no qual quem tem mais espaço e participação nas negociações consegue maiores

Amábili Fraga, Rosa Elisabete Militz Wypyczynski Martins 
As Relações e os Atravessamentos das Questões de Gênero no Ensino: Uma Análise da

Revista Latino-Americana de Geografia e Gênero

representações de seus interesses impressos nesses documentos. Na EJA, reconhecemos um ambiente que recebe pouca visibilidade nas demandas educacionais, não sendo discutidos os problemas de permanência desses jovens e adultos nos espaços formativos.

No que se refere às questões de gênero, segundo o texto, estas possuem níveis e graus de representações diferentes, na qual a mulher, de acordo com a conjuntura em que se encontra, ocupa diferentes espaços nas relações sociais, políticas e culturais, mas constantemente refém da desvalorização. Na esfera da educação abre-se espaço para que esses estigmas sejam sustentados, por esse motivo, que as mudanças no âmbito escolar devem sempre ter como uma das principais pautas as questões de gênero.

'Políticas públicas de gênero no contexto escolar: percepções de orientadoras educacionais' é o último trabalho da categoria educação. Em meio à aprovação do Plano Nacional de Educação e dos Planos estaduais e municipais, surgiram inúmeros movimentos reivindicando a exclusão da categoria de gênero desses documentos. Os discursos, alicerçados em fundamentos religiosos, a partir dos escritos dos(as) autores(as), queriam convencer as autoridades públicas e a sociedade de que a inclusão de gênero e sexualidade nesses planos seriam uma ameaça à família e as crianças. Com base nisso, esse artigo analisa a compreensão de orientadoras educacionais do Ensino Fundamental acerca das políticas públicas de gênero na escola.

Para os(as) autores(as), esse é um campo de pesquisa muito expressivo por conta dos debates e polêmicas que o rodeiam. As políticas públicas são significativas para o (re)conhecimento sobre as desigualdades entre mulheres e homens, assim como para ações que contribuam para a emancipação dos sujeitos discriminados e excluídos. Foi verificado que a temática de gênero e sexualidade no contexto escolar é deficitária, e que grande parte da comunidade escolar segue com uma prática excludente no que versa sobre gênero, rejeitando novos diálogos sobre.

Assim, enquanto esses(as) profissionais continuarem renunciando debates construtivos sobre a temática e sobre atitudes preconceituosas, a escola continuará mantendo e/ou reforçando esses estereótipos. Os resultados revelaram que existe uma carência de conhecimentos acerca das políticas públicas referentes a gênero e destacam a necessidade de inclusão do assunto no espaço escolar. Conclui-se que existe a presença dessas políticas no âmbito escolar, mas é necessário que essas discussões sejam pautadas e incluídas na agenda de reuniões e nas práticas pedagógicas.

Uma das primeiras análises que podemos fazer referente ao gênero tendo como categoria de análise educação, diz respeito ao poder da linguagem. Percebemos que documentos oficiais que tratam das questões de gênero sempre trazendo pronomes no masculino, e mulheres referindo-se a si próprias no masculino, ou professores(as) dirigindo-se a uma turma sempre como eles, revelando sempre um predomínio do masculino sobre o feminino. Ao longo dos artigos analisados, a linguagem por vezes é citada como detentora de um poder simbólico. Mas o que isso quer dizer, de fato? A linguagem perpassa todas as nossas práticas diariamente e acaba assumindo um caráter de naturalidade, mas, em grande parte das vezes, carregado de desigualdades.

Aprendemos na escola as regras gramaticais e a levamos durante a vida sem

Amábili Fraga, Rosa Elisabete Militz Wypyczynski Martins 
As Relações e os Atravessamentos das Questões de Gênero no Ensino: Uma Análise da

Revista Latino-Americana de Geografia e Gênero

grandes questionamentos, "a linguagem não apenas expressa relações, poderes, lugares, ela os institui; ela não apenas veicula, mas produz e pretende fixar diferenças" (LOURO, 2004, p. 66). Como já mencionamos anteriormente, nessa pesquisa, essas considerações já vêm sendo colocadas em voga por estudiosos(as) feministas, mas ainda há grande resistência da sociedade em compreender essas questões. Além do que é dito dos sujeitos a partir do uso das linguagens, é importante que se observe o que não é dito, as demandas que são ocultadas. Aqueles sujeitos que não são, que não estão amparados, por vezes, nem no feminino, nem no masculino, como o ocultamento dos homossexuais (LOURO, 2004). Na educação, a homossexualidade é negada e silenciada pela escola. Por essas razões a linguagem detém desse poder simbólico e está tão ligada as questões da educação.

É importante citar aqui também, a partir das análises, as indagações sobre a representação das masculinidades no contexto escolar, quando falamos sobre gênero, pois é comum que sejam discutidas as questões geradas a partir das desigualdades existentes entre homens e mulheres. Porém, é necessário reconhecer que as masculinidades podem assumir diferentes formas, criando relações de poder dentro dessa categoria. Em um dos artigos foi possível verificar como isso se torna um tema que necessita de discussão no espaço escolar. Quando temos uma turma com meninos e meninas, julga-se "natural" que meninos gostem de esportes, e, ao ser notada a presença de um sujeito que desvia da norma padrão de heteronormatividade, isso é um indício de que alguma coisa "não está certa", dentro de um espaço em que se considera que homens devem gostar de esportes. Dado o momento em que essas situações ocorrem, esses meninos que se distinguem do restante, passam a fazer parte de um grupo refém da discriminação.

A partir da análise dos artigos, percebemos que, tanto para a comunidade escolar quanto para os(as) estudantes, é difícil compreender que, mulheres e homens que vivem feminilidades e masculinidades de formas diversas das hegemônicas, muitas vezes não são representados(as) ou reconhecidos(as) como "verdadeiras/verdadeiros" mulheres e homens" (LOURO, 2004, p. 34). Nesse sentido, percebemos que discutir as questões de gênero dentro da escola são urgentes para que os(as) sujeitos possam se reconhecer e ser respeitados(as), e que a escola ofereça suporte e um espaço que, verdadeiramente, os respeite.

No que tange as questões educacionais quanto ao mercado de trabalho dos profissionais que atuam nesses espaços, foi possível analisar nos artigos como as relações de gênero estão presentes e afetam as interações que acontecem nesses ambientes. Primeiro, podemos constatar a feminização da profissão docente no magistério. As mulheres professoras, ao adentrarem no mercado de trabalho, tiveram seu profissionalismo associado ao cuidado de crianças, ou seja, as representações sociais de homens e mulheres transgrediram para dentro do espaço escolar. Hoje, ainda lidamos com o preconceito com professores homens no que diz respeito ao lecionar para crianças mais novas, mas, quando passamos para os anos mais avançados, a presença de um homem em uma sala de aula, para grande parte da sociedade, impões mais respeito e autoridade com os(as) estudantes.

Essas representações afetam na dinâmica escolar e no dia a dia da sala de

Amábili Fraga, Rosa Elisabete Militz Wypyczynski Martins 
As Relações e os Atravessamentos das Questões de Gênero no Ensino: Uma Análise da

Revista Latino-Americana de Geografia e Gênero

aula, visto que os(as) estudantes estão inseridos nessa cultura. É importante e necessária a quebra desses padrões nesse ambiente, para que esses preconceitos deixem de ser reproduzidos. Verificamos também a ausência da presença de mulheres ocupando cargos nas gestões escolares, esse quadro pode ser considerado uma reprodução da história das discriminações de gênero dentro do mercado de trabalho. As mulheres sempre foram direcionadas a cargos inferiores e subordinados aos homens, por mais que essa situação, hoje, venha se revertendo, ainda vemos os vestígios dessas práticas dentro desses ambientes. Essas questões devem ser levantadas e debatidas, para, além da busca de uma igualdade de gênero nesses espaços, as atividades atribuídas às mulheres sejam respeitadas e valorizadas.

As questões de gênero no ambiente escolar podem contribuir para quebrar com padrões impostos pela sociedade e dar espaços para os outros sujeitos que são considerados invisíveis em diferentes contextos sociais. Quando analisamos como essas questões estão presentes desde a educação infantil, na qual percebemos isso através de gestos, falas, escolha de brinquedos e brincadeiras, assim como a forma de se portar e se relacionar com os(as) demais colegas, verificamos que essas práticas se fixam, inicialmente, no ambiente familiar. As escolhas e percepções do que é feminino ou masculino é adquirida pelas vivências que a criança tem dentro de casa, que depois perpassa por toda a educação escolar, e, muitas vezes, são estereótipos reforçados pela escola.

Por isso, é fundamental trabalhar as relações de gênero na escola para criar movimentos que visam superar as visões estereotipadas dos padrões tidos como normais e aceitáveis, combatendo todas as formas de preconceito existentes. São as convenções que decidem quem está incluso e quem está excluso do ambiente escolar. Quando um(a) estudante se reconhece como um sujeito que desvia do processo de generificação, é, automaticamente ocultado e/ou excluso do espaço escolar, que o torna invisível. Ignorar essa situação faz com que alguns estudantes não queiram frequentar esse ambiente, levando a evasão.

Por fim, na categoria de Educação, foi possível concluir que no contexto escolar, a partir dos trabalhos analisados, que a temática de gênero é deficitária e, por vezes, ausente. A escola segue mantendo práticas excludentes e o corpo escolar segue abdicando desses debates. As políticas públicas que falam sobre gênero, mesmo que por vezes falha, tornam-se utópicas. Essas políticas estão na escola, mas as discussões acerca desse assunto são ocultadas. Todas essas questões, mercado de trabalho, discriminações, políticas, a linguagem na história da educação, enfim, todas as relações que se formam a partir dessas temáticas influenciam na ocupação do espaço e na ressignificação desse. Isto é, são tópicos possíveis de serem explorados aliados as questões de gênero e a educação geográfica, que tem buscando dar contas das mudanças ocorridas na sociedade, e contribuir na formação de estudantes críticos e reflexivos, fugindo do rótulo de uma ciência baseada em memorizações. Hoje e sempre, a geografia escolar é feita no cotidiano e é por esse motivo que abarca as questões de gênero.

Dando continuidade às análises, o Ensino de Geografia como categoria de análise dessa pesquisa apresenta os artigos que correlacionam a temática

Amábili Fraga, Rosa Elisabete Militz Wypyczynski Martins 
As Relações e os Atravessamentos das Questões de Gênero no Ensino: Uma Análise da

Revista Latino-Americana de Geografia e Gênero

gênero com a geografia escolar. A Tabela 2 expõe os artigos selecionados para tal sessão, apresentados por título do trabalho, os autores(as), ano de publicação e o volume e número da edição.

Tabela 2: Artigos da Revista Latino-Americana de Geografia e Gênero selecionados para análise na categoria Ensino de Geografia

\begin{tabular}{|c|c|c|c|c|}
\hline Título & $\begin{array}{r}\text { Categoria } \\
\text { de Análise }\end{array}$ & Autor (a/es) & Ano & $\begin{array}{l}\text { Volume/ } \\
\text { Número }\end{array}$ \\
\hline $\begin{array}{l}\text { A Presença e Ausência } \\
\text { do Debate de Gênero } \\
\text { na Geografia do } \\
\text { Ensino Fundamental e } \\
\text { Médio }\end{array}$ & $\begin{array}{l}\text { Ensino de } \\
\text { Geografia }\end{array}$ & COSTA, Carmem Lúcia & 2011 & $\mathrm{v} 2$ \\
\hline $\begin{array}{lll}\text { Qual Espaço } & \text { para } \\
\text { Discutir Gênero? } & \end{array}$ & $\begin{array}{l}\text { Ensino de } \\
\text { Geografia }\end{array}$ & $\begin{array}{l}\text { SILVA, Telma Ferreira da; } \\
\text { et al. }\end{array}$ & 2014 & v2 \\
\hline $\begin{array}{l}\text { A Geografia } \\
\text { dialogando com as } \\
\text { ciências naturais e as } \\
\text { artes para } \\
\text { compreensão } \\
\text { interdisciplinar } \\
\text { crítica acerca } \\
\text { questões de gênero no } \\
\text { contexto } \\
\text { contemporâneo }\end{array}$ & $\begin{array}{l}\text { Ensino de } \\
\text { Geografia }\end{array}$ & \begin{tabular}{|lr} 
FREITAS, Bruno & de; \\
BERNARDES, & Maria \\
Beatriz Junqueira &
\end{tabular} & 2014 & v2 \\
\hline $\begin{array}{lr}\text { A utilização da mídia } \\
\text { publicitária no } & \text { ensino } \\
\text { de geografia: } & \text { uma } \\
\text { oficina pedagógica } \\
\text { acerca } & \text { da } \\
\text { discriminação } & \text { da } \\
\text { mulher } & \end{array}$ & $\begin{array}{l}\text { Ensino de } \\
\text { Geografia }\end{array}$ & $\begin{array}{lr}\text { BRANDÃO, } & \text { Jéssica } \\
\text { Justino; } & \text { FONSECA, } \\
\text { Ricardo Lopes } & \end{array}$ & 2016 & $\mathrm{v} 1$ \\
\hline
\end{tabular}

Fonte: Elaborada pela autora, 2019.

'A Presença e Ausência do Debate de Gênero na Geografia do Ensino Fundamental e Médio' é uma pesquisa que analisa como as mulheres são abordadas dentro da Geografia e como essa ciência pode auxiliar nos debates acerca do tema em sala de aula. São trabalhadas as questões de gênero na ciência geográfica e nos livros didáticos de geografia. Versar sobre gênero é questionar a atual organização social, formada por ideologias e métodos machistas de dominação. Esse trabalho se debruça em como as relações entre os sujeitos são trabalhadas e como se reproduzem no espaço, tendo como recorte o livro didático para análise dessas dinâmicas.

A categoria de gênero é tratada, por parte das autoras, a partir de um viés geográfico, considerando que as relações sociais auxiliam na reprodução do espaço. Com a seleção de três livros didáticos distintos, o trabalho buscou identificar onde e de que maneira as relações de gênero estão expressas, observando como as mulheres estão presentes nesses materiais e quais as influências e papéis que essas têm na construção do espaço.

Com as análises dos livros, a autora concluiu que a categoria de gênero não é tratada de forma direta, havendo apenas pequenas passagens sobre a situação

Amábili Fraga, Rosa Elisabete Militz Wypyczynski Martins 
As Relações e os Atravessamentos das Questões de Gênero no Ensino: Uma Análise da

Revista Latino-Americana de Geografia e Gênero

das mulheres no Brasil e no mundo, necessitando de uma releitura do papel dessas ao longo da história para reconhecer as diferenças que são reproduzidas como desigualdades. O livro didático se mostra como um material de reprodução da heteronormatividade, reproduzindo alienação e segregação. Com isso, é importante que o(a) professor(a) em sala de aula, dê destaque ao trabalho que possibilite a abordagem de gênero como uma categoria social de análise, que minimize as desigualdades entre homens e mulheres em nossa sociedade.

$\mathrm{O}$ artigo 'A Geografia dialogando com as ciências naturais e as artes para a compreensão interdisciplinar e crítica acerca de questões de gênero no contexto contemporâneo' tem como objetivo exibir os resultados alcançados a partir de uma atividade interdisciplinar, realizada em uma turma de $8^{\circ}$ ano.

A atividade baseou-se em possibilitar a compreensão da mulher no mundo contemporâneo, unindo as disciplinas de Geografia, Artes e Ciências Naturais, pautada nos temas transversais de Orientação Sexual e Pluralidade Cultural. Dessa forma, foi proposto aos(às) estudantes que reconhecessem essas indagações a partir de um viés interdisciplinar. Assim, a partir da realização das atividades, esses estariam aptos(as) a observar e reconhecer as atividades presentes à sua volta, formando-se como cidadão(a) crítico(a) e reflexivo(a). Com a aplicação da atividade proposta, os autores(as) buscavam difundir na escola a concepção de cidadania e seu exercício.

Dentro das Ciências Naturais, a intenção era denunciar as concepções sociais e culturais referentes ao que reconhecemos como masculino e feminino, descartando o determinismo biológico, fazendo com que os(as) estudantes compreendam as concepções de sexo, identidade de gênero e orientação afetivosexual. No que tange o ensino de Geografia para a compreensão dessas temáticas, essa assume o papel de trabalhar as questões de culturais de gênero na contemporaneidade, percebendo as características de ser mulher a partir de diferentes regiões do globo. A geografia como ciência auxilia na compreensão do papel da mulher na sociedade reconhecendo as especificidades do espaço e a ocupação desse. Ela possibilita que os(as) estudantes façam relações com a mulher e o mercado de trabalho, questões culturais e étnicas a partir do lugar.

Por fim, o estudo das Artes contribui na representação da temática a partir de uma linguagem artística, ligada a escrita. Através das atividades interdisciplinares os(as) autores(as) puderam destacar a utilização de temas transversais, possibilitando a representação feminina de maneira subjetiva, fazendo com que os(as) educandos(as) compreendessem as questões de gênero e o papel da mulher na sociedade.

'Qual Espaço para Discutir Gênero?', é um trabalho feito, na sua maior parte, por geógrafas, que reflete a respeito das discussões de gênero no âmbito educacional. Com uma metodologia participativa, a pesquisa busca entender como os(as) estudantes percebem as questões relacionadas a mulher na sociedade e no cotidiano. Os sujeitos de pesquisa foram estudantes de uma turma jovens e adultos do Ensino de Jovens e Adultos (EJA) do período noturno em uma escola estadual. Foram elaboradas três perguntas chave que movimentariam a pesquisa, sendo essas 'o que entendem sobre gênero?', 'o que é feminismo e feminino?' e 'há conversa em casa sobre a relação de

Amábili Fraga, Rosa Elisabete Militz Wypyczynski Martins 
As Relações e os Atravessamentos das Questões de Gênero no Ensino: Uma Análise da

Revista Latino-Americana de Geografia e Gênero

gênero?'. As pesquisadoras declaram a escola como um lugar de ensino, em que a construção dos saberes deve ser alcançados de forma consciente com o envolvimento de todos(as) os(as) estudantes nas propostas pedagógicas a partir das experiências.

Assim, a Geografia como disciplina escolar deve movimentar a criticidade dos(as) estudantes com temas que abordem a compreensão das questões de gênero. Para as autoras, trabalhar gênero na geografia assume tecer redes de convívio na sociedade a partir das ações sociais. Assim, as discussões apresentadas nesse trabalho levam em consideração as especificidades das condições do espaço. A partir das entrevistas, é possível perceber que as concepções quanto ao significado de gênero são fundamentadas no que é visto na mídia, de forma descompromissada com a qualidade do que ensina, e que modela o saber desses sujeitos. Conclui-se que é necessário debater acerca das questões sobre gênero desde o convívio familiar, no qual homem e mulher já devem se reconhecer como sujeitos iguais perante as oportunidades, consolidando relações de igualdade na sociedade.

Finalmente, em 'A utilização da mídia publicitária no ensino de geografia: uma oficina pedagógica acerca da discriminação da mulher', traz uma discussão sobre como os meios de publicidade reforçam as desigualdades de gênero, retratando as mulheres como inferiores aos homens. Tem como objetivo discutir como a publicidade pode auxiliar nos debates sobre as discriminações de mulheres na escola, e como isso afeta e modifica as relações de apropriação do espaço geográfico. Problematizar as maneiras de como as mulheres são representadas na mídia pode ser uma temática trabalhada na sala de aula, enriquecendo o debate sobre as questões de gênero.

Essa pesquisa é resultado de oficinas realizadas com estudantes do terceiro ano de uma escola estadual. Por meio das atividades, buscou-se investigar como materiais midiáticos podem auxiliar na discussão dessa temática e como isso, dentro da ciência geográfica, relacionar com os problemas sociais. Com as oficinas, os(as) autores(as) tinham a intenção de fazer com que os(as) estudantes compreendessem a apropriação do espaço e como as relações de gênero afetam essa dinâmica, na qual as desigualdades fazem homens e mulheres ocuparem esse espaço de formas diferentes.

Os(as) estudantes, segundo os(as) autores(as), perceberam, através de notícias e propagandas, as discriminações com a mulher na sociedade, refletindo na forma em como esses materiais representam o feminino. Porém, tiveram dificuldades em relacionar isso a produção e reprodução espacial, ou seja, em associar o tema aos aspectos geográficos. Por fim, os autores(as) afirmam que no decorrer das atividades surgiram falas e atitudes machistas, que mostram a necessidade de realizar essas discussões e análises no espaço escolar, e, principalmente, na geografia escolar, suprindo a carência dos(as) estudantes de reconhecerem as questões de gênero como uma temática de estudo dessa disciplina.

Com a leitura dos artigos selecionados nessa categoria de análise, foi possível verificar que ao levar as questões de gênero para dentro das salas de aula, nos deparamos com um ambiente escolar ainda muito carente desses debates. A ciência geográfica oferece um leque de possibilidades para que essas questões sejam abordadas e no que tange a mesma como disciplina

Amábili Fraga, Rosa Elisabete Militz Wypyczynski Martins 
As Relações e os Atravessamentos das Questões de Gênero no Ensino: Uma Análise da

Revista Latino-Americana de Geografia e Gênero

escolar, os conteúdos a serem trabalhados também oportunizam a abertura dessas discussões. Seja na ocupação do espaço público ou privado e formação das cidades, nas relações de trabalho, nas questões referentes à violência contra a mulher, representação do masculino e feminino nas mídias e materiais didáticos, nos movimentos sociais, entre outros assuntos, a geografia abre espaço para que esses temas sejam trabalhados a partir das relações de gênero.

Foi possível perceber que, a partir dos resultados e discussões dos trabalhos analisados, as questões de gênero são, na maioria das vezes, ausentes não só no ambiente escolar, mas também no ambiente familiar, ou seja, os(as) estudantes chegam na escola sem base sobre a importância do reconhecimento das diversidades. A escola, que se mantém como um espaço que continua configurado numa ótica de heteronormatividade, recebe esses(as) estudantes e os(as) auxilia no processo de amadurecimento de suas identidades, que se reproduzem dentro do que é imposto como padrão, sem que esse seja questionado. Com isso, as identidades que desviam desse padrão são consideradas diferentes e sofrem a partir de relações de desigualdade.

Quando recorremos aos materiais didáticos de geografia, encontramos o mesmo cenário, uma geografia ausente de debates de gênero, que não trabalha nem problematiza as relações de poder diante da exploração das mulheres em relação aos homens. Com isso, é importante que o(a) professor(a) traga o debate para a sala de aula, questione o papel dos materiais didáticos na formação dos(das) estudantes. Estas ausências contribuem para que a mulher continue fazendo parte de um extrato social com uma cultura negada ${ }^{1}$, que segue os padrões culturalmente impostos.

Embora que as pesquisas, dentro do âmbito da geografia, que abordam as questões de gênero venham crescendo no campo acadêmico, no que tange o ensino de geografia foi possível analisar que essas ainda são pouco representativas. Com a seleção de apenas quatro artigos dentro dessa categoria, percebemos a necessidade de investir nesse campo de pesquisa dentro do espaço escolar. A geografia, enquanto disciplina escolar, tem um papel importante na formação da consciência crítica dos(das) estudantes sobre a realidade social e o seu papel na produção do espaço. É importante que esse movimento se desenrole num viés pautado na valorização das relações de gênero, para que estejam aptos a reconhecer as diversidades.

\section{Considerações Finais}

Esse trabalho foi pautado na problemática de compreender qual a potência educativa das produções científicas da Revista Latino-americana de Geografia e Gênero sobre os estudos de gênero e, como, a partir disso, é possível movimentar outras geografias.

Com o propósito de identificar a trajetória dos estudos de gênero a partir da história do movimento feminista contemporâneo e a relevância dessas questões nos diferentes espaços de ensino, esse trabalho se iniciou com o histórico da introdução do uso de gênero como uma categoria de análise a partir dos

1 O termo cultura negada, a partir de Tonini (2002) apud. Santomé (1995) faz referência a um grupo da sociedade que acaba por ser excluído, ocupando posições inferiorizadas no quadro das estruturas socioeconômicas.

Amábili Fraga, Rosa Elisabete Militz Wypyczynski Martins 
As Relações e os Atravessamentos das Questões de Gênero no Ensino: Uma Análise da

Revista Latino-Americana de Geografia e Gênero

estudos feministas e a importância dessas indagações na educação e no ambiente escolar. Foi possível constatar que os estudos de gênero e as questões que envolvem as mulheres são pautas cada vez mais presentes na sociedade. Apesar disso, vimos que essas discussões ainda encontram muitas barreiras para se inserirem nos espaços educativos. A problematização e compreensão das relações de poder geradas a partir das relações de gênero permite que os(as) estudantes reconheçam a existência de diferentes identidades, combatendo-se assim, as discriminações e corroborando para um ambiente menos desigual. Inserir as questões de gênero dentro dos espaços escolares vai de encontro com alcançar a equidade e o respeito aos direitos humanos na sociedade.

$\mathrm{Na}$ busca por compreender a importância dos estudos de gênero no âmbito da geografia, essa pesquisa buscou problematizar a ausência dessa temática na ciência geográfica, encontrando um cenário de abertura para essas pautas dentro da geografia, observando-se apontamentos iniciais sobre o tema dentro da geografia escolar. Ao afirmar que as relações de gênero influenciam nas formas de ocupação do espaço, a partir das relações traçadas nesse, e que a geografia como ciência compreende as formas da apropriação desse espaço, avalio aqui que é indispensável trabalhar a temática de gênero dentro da geografia. Foi possível analisar, dentro dos artigos apreciados na revista, que a ciência geográfica nesse contexto se identifica como uma ciência majoritariamente masculina e, por mais que as mulheres venham ganhando seu espaço nessa, as questões de gênero ainda são pouco trabalhadas e problematizadas. Foi nessa ausência de mulheres no campo da geografia que surgiram as geografias feministas, reivindicando novas versões científicas para essa ciência, que, aos poucos, tem absorvido os trabalhos femininos.

A análise social desses estudos permite que os(as) estudantes compreendam as diferentes formas de empoderamento do local por parte dos diferentes grupos sociais. Visto que apreender as relações de gênero apoiada numa perspectiva geográfica permite caracterizar o espaço como fruto das interrelações que ocorrem nesse meio. A geografia fornece aos(as) estudantes formas de entender a realidade social, reconhecendo as maneiras com que essa se relaciona com o meio e com a remodelação desse espaço. Neste sentido, a geografia escolar tem um papel importante de formar estudantes críticos(as) e conscientes do seu papel na sociedade. Posto isso, aliar os conhecimentos desta ciência as questões de gênero, contribui na formação de sujeitos preparados para reconhecer e respeitar uma sociedade plural.

Ao realizar um mapeamento dos artigos que tratam dos estudos de gênero na Revista Latino-americana de Geografia e Gênero, a partir dos indicadores de análise: educação e ensino de geografia, doze artigos selecionados foram divididos entre as duas categorias. Posto isso, foram alocados oito artigos no corpo de análise da categoria Educação. Sendo possível verificar a importância dos estudos de gênero nas mais diversas áreas do campo da educação. Tratar as relações de gênero na educação consiste em trabalhar com diversidades em movimento, desmistificando padrões construídos socialmente. Assim, a possibilidade de transformação das relações sociais encontra um ponto de apoio nos estudos de gênero na educação, confrontando uma sociedade heteronormativa. Combinar os estudos de gênero à educação auxilia na busca

Amábili Fraga, Rosa Elisabete Militz Wypyczynski Martins 
As Relações e os Atravessamentos das Questões de Gênero no Ensino: Uma Análise da

Revista Latino-Americana de Geografia e Gênero

políticas de construção do espaço respeitando as diferenças de gênero.

Ao passo em que a importância desses estudos na educação vem sendo reconhecida, ainda nos deparamos com muitas barreiras a serem enfrentadas. Existe, ainda, muita resistência em discutir esse assunto nos espaços formativos. A sociedade ainda reconhece gênero como uma "ameaça" à escola, à família e às crianças. Assim como ainda defendem a construção dos sujeitos a partir do determinismo biológico, tornando invisível quem desvia do padrão homem e mulher imposto pela heteronormatividade. Essa prática pode ser vista, também dentro da escola, de acordo com os trabalhos. A escola conserva essas práticas excludentes e desconsidera os debates de gênero. Já existem políticas que trabalham com gênero dentro do ambiente escolar a partir de um viés de transversalidade, mas ainda percebemos que faltam debates nas salas de aulas que possibilitem refletir acerca destas temáticas.

Na categoria de Ensino de Geografia, analisamos um total de quatro artigos, o que demonstra uma presença muito tímida relacionada à temática de gênero na educação geográfica. A partir dos estudos realizados sobre gênero na geografia e a partir da análise dos artigos selecionados, foi possível confirmar como a geografia como disciplina escolar é pouco representativa no que toca trabalhar as questões de gênero no seu ensino. São muitas as temáticas que podem ser trabalhadas a partir da geografia pautadas nos estudos de gênero, como já foram citadas nesse trabalho. A geografia escolar tem um papel fundamental na formação cidadã dos(das) estudantes enquanto sujeitos protagonistas da sua história. Associar os estudos de gênero nesse processo formativo contribui na formação de sujeitos críticos(as) da sua representação na ocupação do espaço, valorizando, reconhecendo e respeitando as diversidades que também estão presentes nessa produção.

Verificamos que as mais diversas áreas de estudo da geografia, como a ocupação do espaço, as relações de trabalho, políticas, questões sobre o estudo e representação de mulheres, violência, entre outros, assim como a desconstrução de materiais didáticos que carregam estereótipos de gênero e pouca representatividade feminina são temáticas possíveis de se estudar fazendo relação com a educação geográfica e os estudos de gênero, fugindo de uma ciência de memorização e valorizando a sociedade plural. Hoje, nós precisamos de estudos que, além das complexidades da sociedade, compreendam também as relações socioespaciais, focando nos diferentes sujeitos que estão nesse espaço. Assim, a geografia pode contribuir para minimizar o desrespeito, utilizando os estudos e pesquisas de gênero para colaborar com as reflexões acerca de uma sociedade diversificada. Essas questões necessitam ser atravessadas pela geografia, que é uma ciência que busca problematizar práticas cotidianas que normalizam as desigualdades no dia a dia, na busca de romper com estereótipos estabelecidos pelas relações de poder entre homens e mulheres.

\section{Referências}

BASILIO, Luciana. As Educadoras e o Sistema de Ensino do Município de Porto Velho: Uma História de Ausências. Revista Latino-americana de Geografia e Gênero, v. 5, n. 2, p. 209 - 229, 2014.

Amábili Fraga, Rosa Elisabete Militz Wypyczynski Martins 
As Relações e os Atravessamentos das Questões de Gênero no Ensino: Uma Análise da

Revista Latino-Americana de Geografia e Gênero

BRANDÃO, Jéssica Justino; FONSECA, Ricardo Lopes. A Utilização da Mídia Publicitária no Ensino de Geografia: Uma Oficina Pedagógica acerca da Discriminação da Mulher. Revista Latino Americana de Geografia e Gênero, v. 10, n. 1, p. 181 - 196, 2019.

BRASIL. Ministério da Educação. Secretaria de Educação Fundamental. Parâmetros Curriculares Nacionais: apresentação dos temas transversais. Brasília: MEC/SEF, 1998a.

BRITO, Leandro Teofilo de; FREITAS, José Guilherme de Oliveira; SANTOS, Mônica Pereira dos. "Não, Isso não é Coisa pra Homem" - Masculinidades e os Processos de Inclusão/Exclusão em uma Escola da Baixada Fluminense RJ. Revista Latino-americana de Geografia e Gênero, v. 5, n. 2, p.114 - 125, 2014.

CALLAI, Helena Copetti. A geografia escolar - e os conteúdos da Geografia. Anekumene: Geografia, cultura y educación, v. 1, p.128 - 139, 2011.

CORRÊA, Anderson Rodrigues; FREITAS, Letícia Fonseca Richthofen de. A escola em diáspora. Revista Latino-americana de Geografia e Gênero, v. 2, n. 2 , p. $85-92,2011$.

CORREIO, Juliana Lopes Garcia; TOSCANO, Carlos. Significações de um personagem de desenho animado no espaço escolar: um estudo sobre gênero na Educação Infantil. Revista Latino-americana de Geografia e Gênero, v. 7, n. 1, p. 98 - 108, 2016.

COSTA, Carmem Lúcia. A presença e ausência do debate de gênero na geografia do Ensino Fundamental e Médio. Revista Latino-americana de Geografia e Gênero, v. 2, n. 2, p. 76 - 84, 2011.

FERREIRA, Telma et al. Qual Espaço para Discutir Gênero? Revista Latinoamericana de Geografia e Gênero, v. 6, n. 1, p. 169 - 183, 2015.

FREITAS, Bruno; BERNARDES, Maria Beatriz Junqueira. A Geografia dialogando com as ciências naturais $\mathrm{e}$ as artes para a compreensão interdisciplinar e crítica acerca de questões de gênero no contexto contemporâneo. Revista Latino-americana de Geografia e Gênero, v. 7, n. 2, p. $105-129,2016$.

FURLANI, Jimena. Educação Sexual na sala de aula: relações de gênero, orientação sexual e igualdade étnico-racial numa proposta em respeito às diferenças. 1 ed. Belo Horizonte: Autêntica, 2016.

GONÇALVES, Josiane Peres; CARVALHO, Viviane de Souza Correia de. Estudo das Representações Sociais de Professores Homens de Mato Grosso do Sul Sobre o Trabalho Realizado com Crianças. Revista Latino-americana de 
As Relações e os Atravessamentos das Questões de Gênero no Ensino: Uma Análise da

Revista Latino-Americana de Geografia e Gênero

Geografia e Gênero, v. 7, n. 2, p. 93 - 104, 2016.

GRAUPE, Mareli Eliane; LOCKS, Geraldo Augusto; SOUSA, Lúcia Aulete Búrigo de. Políticas públicas de gênero no contexto escolar: percepções de orientadoras educacionais. Revista Latino-americana de Geografia e Gênero, v. 10, n. 1, p. 197 - 213, 2019.

HONORATO, Rafael Ferreira de Souza; PEREIRA, Maria Zuleide da Costa. Gênero nas Políticas Educacionais do Estado da Paraíba: (Des)Continuidades. Revista Latino-americana de Geografia e Gênero, v. 8, n. 2, p. 263 - 283, 2017.

LOURO, Guacira Lopes. Gênero, sexualidade e educação: Uma perspectiva pós-estruturalista. Petrópolis, RJ: Vozes, 2004.

OLIVEIRA JÚNIOR, Isaias Batista de; OLIVEIRA, Marta Regina Furlan de; MAIO, Eliane Rose. Alienígenas na Escola: Corpos que Escapam ao Processo de Re/Produção dos Gêneros Imutáveis. Revista Latino-americana de Geografia e Gênero, v. 8, n. 1, p. 385 - 405, 2017.

PETITAT, André. Produção da escola/produção da sociedade: análise sócio histórica de alguns momentos decisivos da evolução escolar no ocidente. Porto Alegre: Artes Médicas, 1994.

REIS, Maíra Lopes. Estudos de gênero na geografia: uma análise feminista da produção do espaço. Espaço e Cultura, v. 38, p. 11 - 34, 2015.

RIBEIRO, Ddjamila. Quem tem medo do feminismo negro? São Paulo, SP: Companhia das Letras, 2018.

SCOTT, Joan. Gênero: uma categoria útil de análise histórica. Educação e realidade, v. 20, n. 2, p. $71-97,1995$.

SILVA, Joseli Maria. Geografias Subversivas: discursos sobre espaço, gênero e sexualidades. 1 ed. Ponta Grossa: Todapalavra, 2009b.

SILVEIRA, Denise Tolfo; CÓRDOVA, Fernanda Peixoto. A pesquisa científica. In: GERHARDT, Tatiana Engel; SILVEIRA, Denise Tolfo (Org.). Métodos de pesquisa. Porto Alegre: Editora da Ufrgs, 2009, p. 31 - 42.

TONINI, Ivaine Maria. Identidades capturadas: gênero, geração e etnia na hierarquia territorial dos livros de geografia. 2002. Tese (Doutorado em Educação) - Programa de Pós-Graduação em Educação, Faculdade de Educação, Universidade Federal do Rio Grande do Sul, Porto Alegre.

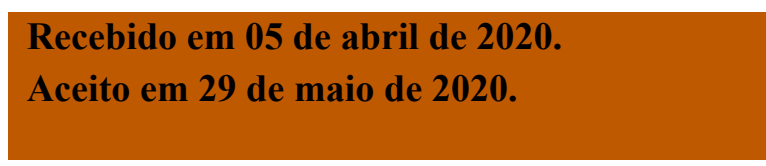

Amábili Fraga, Rosa Elisabete Militz Wypyczynski Martins 